\title{
Interaction between the vertical distribution of juvenile walleye pollock Theragra chalcogramma in the eastern Bering Sea, and cannibalism
}

\author{
Kevin M. Bailey \\ Northwest and Alaska Fisheries Center, National Marine Fisheries Service, NOAA, 7600 Sand Point Way NE, Seattle, \\ Washington 98115 , USA
}

\begin{abstract}
In autumn 1984 the interaction of vertical migration of age-0 walleye pollock Theragra chalcogramma in the eastem Bering Sea, and cannibalism was examined. Patterns of vertical migration were inferred from acoustic observations, midwater trawls, and occurrence of juveniles in the stomachs of adults caught in bottom trawls. Generally, most age-0 pollock were distributed in the near-surface layer at night. During the day larger individuals moved through the thermocline into the bottom layer. Variations in migratory patterns were observed and are discussed in relation to the thermocline, zooplankton abundance, growth, and size. Age-0 juveniles from 50 to $60 \mathrm{~mm}$ ate mostly large copepods. At 3 stations the growth of juveniles, as inferred from otolith increment widths for the $10 \mathrm{~d}$ prior to capture, increased with zooplankton abundance. Of 1503 adult pollock stomachs, $29 \%$ contained juvenile pollock, all of which were age-0 fish, 20 to $100 \mathrm{~mm}$ in length. Adult pollock contained an average of 3.0 juveniles per stomach. The size composition of juveniles in adult stomachs and the diurnal pattern of adult pollock feeding on juveniles indicated that cannibalism occurred mostly in daytime and was closely coupled with vertical distribution patterns of juveniles
\end{abstract}

\section{INTRODUCTION}

The migratory patterns of juvenile marine fishes and the factors affecting them are not well-known, in spite of the importance of the resulting distribution to juvenile ecology and assessment of abundance (Koeller et al. 1986). Habitat shifts during the transitional juvenile stage make them particularly difficult to sample. From an ecological perspective, vertical migration influences feeding habits (Mahon \& Neilson 1987) and may be important in exposing juveniles to abundant bathypelagic or demersal predators. This appears to be the case for walleye pollock Theragra chalcogramma; after transition from pelagic larvae to vertically migrating juveniles, young walleye pollock become prey to numerous fishes, especially cannibalistic adults. The objective of this study was to examine the interaction between vertical distribution of age- 0 walleye pollock and cannibalism.

Cannibalism by walleye pollock in the eastern Bering Sea is an important feature in its population dynamics (Mito 1974, Bailey \& Dunn 1979). Dwyer et al. (1987) found that $96 \%$ of juvenile walleye pollock consumed by adults were age-0 fish, mostly eaten in autumn and winter; little cannibalism occurred on age- 0 walleye pollock in spring or summer. Adult walleye pollock generally inhabit waters near bottom over the continental shelf and midwater over deep basins (Maeda 1986, Okada 1986). In summer, age-0 fish are in the surface layer (upper $40 \mathrm{~m}$ of the water column), within or above the thermocline (Maeda 1986, Nishiyama et al. 1986). Francis \& Bailey (1983) hypothesized that age-0 walleye pollock become vulnerable to cannibalism in autumn when the thermocline breaks down due to wind mixing and surface cooling, and juveniles are recruited to the bottom layer inhabited by adults.

In this study I describe the vertical distribution of juvenile pollock in relation to the thermocline during the critical autumn season, thus testing the above hypothesis. The interaction of vertical distribution and cannibalism is examined and the influence of feeding habits and growth on vertical migration is discussed. 


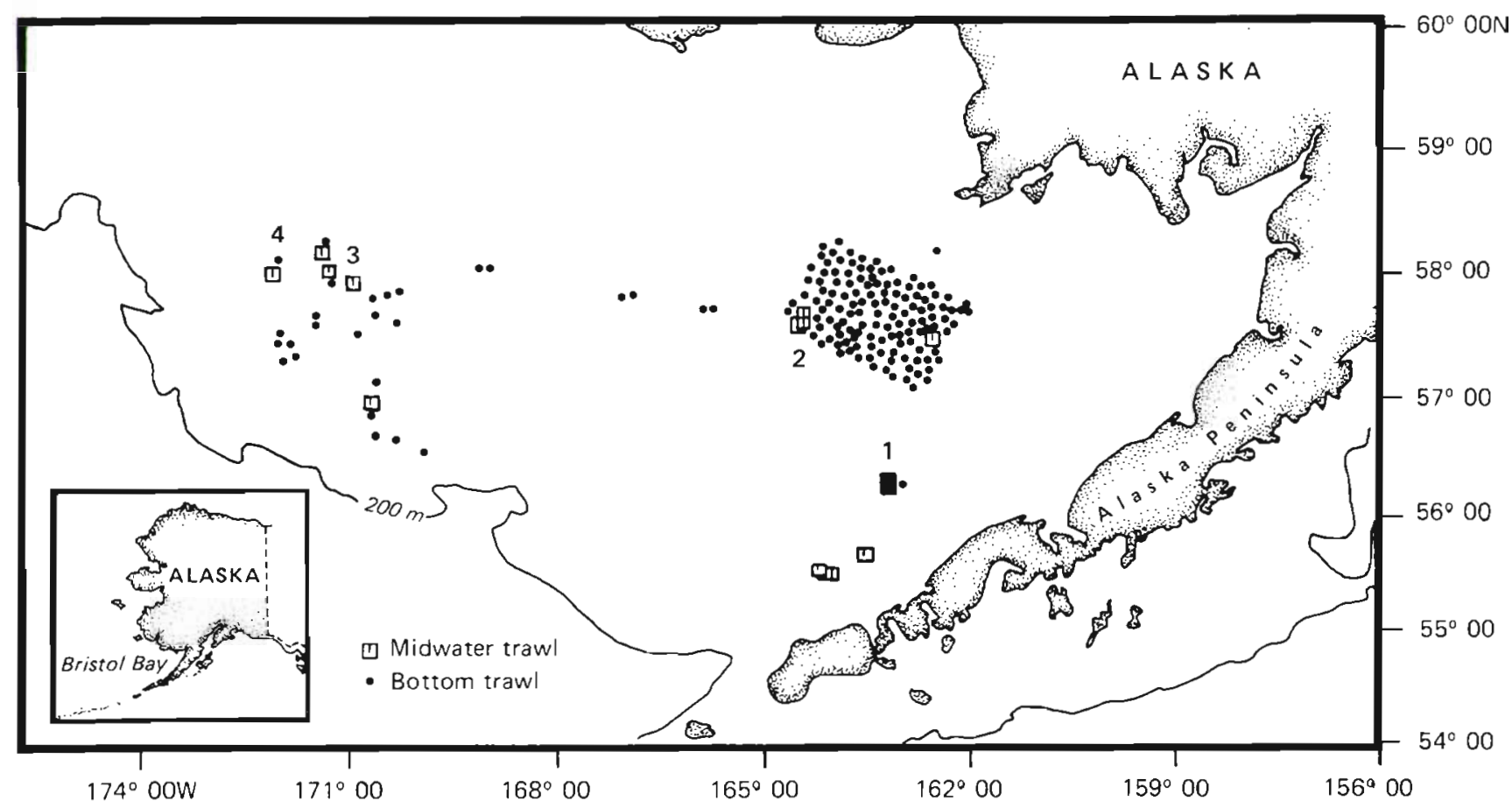

Fig. 1. Distribution of Marinovich midwater and Eastern bottom trawls. Numbers refer to stations discussed in text

\section{METHODS}

Data on juvenile walleye pollock were collected during a bottom trawl survey on RV 'Miller Freeman' from 23 August to 14 September 1984 in the eastern Bering Sea. The area of operation and location of special stations for juvenile studies are shown in Fig. 1. Data collected at individual stations during the course of this cruise were of 3 types. (1) Hydroacoustic observations, CTD (conductivity-temperature-depth) casts and adult stomach content analyses were made at most bottom trawl stations during the cruise. (2) At several stations bottom trawls were accompanied by midwater and plankton hauls. (3) At Stn 1 and 2, midwater, bottom and plankton hauls were conducted continuously during a 24 h occupation.

An 83-112 Eastern bottom trawl with $1.8 \times 2.7 \mathrm{~m}$ doors was towed for $30 \mathrm{~min}$ at depth. Adult walleye pollock from 85 bottom trawl catches were examined for evidence of cannibalism; shipboard stomach analysis was conducted on 1503 fish, excluding discards. Fish showing evidence of net feeding or regurgitation, i.e. extremely fresh prey, prey in the throat, or flaccid stomachs, were discarded. In general, age-0 walleye pollock were not retained in the Eastern bottom trawls, minimizing the occurrence of net feeding. Fish prey positively identified as walleye pollock were enumerated and measured (fork length).

Hydroacoustic observations were made using a Sim- rad EQ-38" echosounder, interfaced with a JRC16 color sounder recorder.

Nineteen midwater trawls for juvenile pollock were made using a Marinovich trawl with $1.5 \times 2.1 \mathrm{~m}$ doors. When towed at 3 knots, the vertical mouth opening was 3 to $5 \mathrm{~m}$. Stretched mesh size was $76 \mathrm{~mm}$ in the forward part of the net and $28 \mathrm{~mm}$ in the codend. The final $1 / 3$ of the codend was lined with $3 \mathrm{~mm}$ netting. The trawl was positioned vertically in surface or bottom layers of the water column using a third wire net sounder transducer with a Simrad-50 echo sounder, held at the desired (equilibrium) depth for 20 to $30 \mathrm{~min}$ and then retrieved as quickly as possible. The depth of trawl was based on the acoustic signal. When the acoustic signal was weak, collections were taken at a predetermined depth above or below the thermocline. Juvenile fish were preserved in $90 \%$ ethanol or frozen for stomach content analysis.

Plankton tows were made with a $60 \mathrm{~cm}$ bongo frame equipped with $333 \mu \mathrm{m}$ nitex mesh netting. Tows were oblique from $10 \mathrm{~m}$ off bottom or $200 \mathrm{~m}$ depth whichever was greatest. The ship's speed was 2 knots Plankton were fixed in $5 \%$ buffered formalin. Blotted wet weights of zooplankton were determined after removing large jellyfish, and samples were sorted to gross taxa.

\footnotetext{
- Reference to trade names does not imply endorsement by the National Marine Fisheries Service, NOAA.
} 
Growth of juvenile walleye pollock was estimated from the width of the 10 most distal increments deposited on the anterior end of the otolith. The right otolith, removed from frozen and ethanol-preserved specimens was mounted in Histoclad, ground with 1500 grit sandpaper, and polished with $5 \mu \mathrm{m}$ grit polishing compound, or with 1200 grit sandpaper and $3 \mu \mathrm{m}$ diamond paste. Otoliths were etched with $8 \%$ EDTA ( $\mathrm{pH} 8$ ) for 5 to $15 \mathrm{~min}$ or with $25 \%$ citric acid for 30 to 120 $\mathrm{s}$. The widths of the last 10 increments deposited on the anterior edge of the otolith were measured at 125 or 500 $x$ with a compound microscope equipped with an ocular micrometer. To verify increment structure identified by light microscopy, some otoliths were coated with goldpalladium and viewed with an AMR 1000 scanning electron microscope. Daily deposition of increments on walleye pollock otoliths has been previously validated (Nishimura \& Yamada 1984, Bailey \& Stehr 1988).

\section{RESULTS}

\section{Vertical distribution patterns}

Patterns of vertical distribution of age- 0 walleye pollock were determined from hydroacoustic observations, midwater trawling and occurrence in adult stomachs.

Acoustic signal strength was compared with midwater trawl catches at 19 stations. Relative signal strengths, determined from visual inspection of the paper traces, were subjectively classified into light (1), medium (2), and heavy (3) scattering layers of juvenile pollock at the equilibrium depth of the midwater trawl. Comparison of relative signal strength and numbers of juvenile pollock caught per min trawled showed fairly good agreement (Fig. 2). In the 5 tows with light scattering layers, catches of pollock were low. Heavy sig-

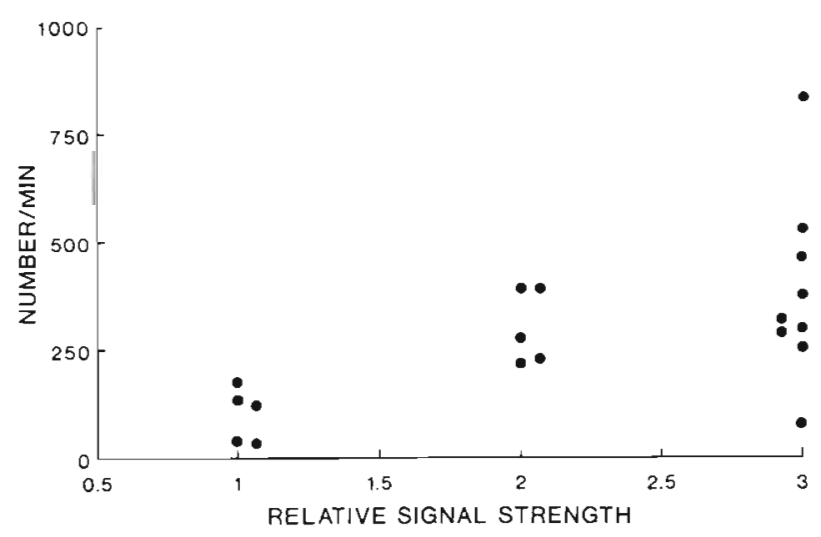

Fig. 2. Theragra chalcogramma. Relative acoustic signal strength at the equilibrium depth of midwater trawl, compared with catches of juvenile walleye pollock nals were accompanied by high catches with the exception of 1 station. At this station the trawl depth (which was very near bottom) may have been below the main location of juveniles. Overall, pollock catches in the light, medium and heavy layers were significantly different (Kruskal-Wallis test $H$ statistic $=9.1$, $0.01<p<0.025$; Zar 1984). Multiple comparison tests showed that catches in heavy layers were significantly different from those in light layers $(0.005<p<0.01)$; differences in catches in medium and light layers were near significant $(0.05<p<0.10)$, but catches in medium and heavy layers were not significantly different $(p>0.50)$.

Large-sized jellyfish dominated midwater trawl catches ( $86.9 \%$ by weight) followed by juvenile pollock $(11.6 \%)$. Although high concentrations of jellyfish could have interfered with acoustic signals, the relationship between jellyfish catches and relative acoustic signal strength was not significant (Kruskal-Wallis $H$ statistic $=1.45,0.25<p<0.50$ ). Since jellyfish are poor sound scatterers at $38 \mathrm{kHz}$, it is believed that fishes were the primary scatterers (Traynor 1986). Jellyfish may have appeared more abundant from trawl catches because juvenile fishes are sampled relatively poorly with the Marinovich trawl (Traynor 1986) compared to large jellyfish. Of fishes caught, juvenile pollock were most abundant ( $88.9 \%$ by weight).

The vertical distribution and migration patterns of juvenile walleye pollock were compared at 2 stations which were occupied continuously for $24 \mathrm{~h}$. Both Stn 1 and 2 were located over the middle shelf at depths of 47 and 30 fathoms ( $\mathrm{fm}$ ) (86 and $55 \mathrm{~m}$ ), respectively. In this paper the surface layer was defined as that part of the water column above the thermocline. The bottom layer was defined as that part below the thermocline, or where no thermocline existed, as the lower half of the water column.

Acoustic observations at Stn 1 indicated vertical migration by a portion of juvenile pollock to the surface layer at night, and into the bottom layer in daytime (Fig. 3). Midwater trawl data revealed 2 apparent length modes of age-0 juveniles, at 50 to $59 \mathrm{~mm}$ and 70 to $89 \mathrm{~mm}$ (Fig. 4). This bimodal distribution has been observed previously (Traynor 1986). The smaller mode was not abundant in bottom layer midwater trawls taken during day or night, indicating that this component was not migrating vertically. Daytime catches of fish in the larger size mode in the bottom layer were double those of night-time catches there; night-time catches of this size mode were more abundant in surface layer trawls compared with bottom layer midwater trawls. These results support the acoustic observations of diel vertical migration of juveniles upwards at night and downwards in the day, and indicate that large juveniles were the migrating component. 


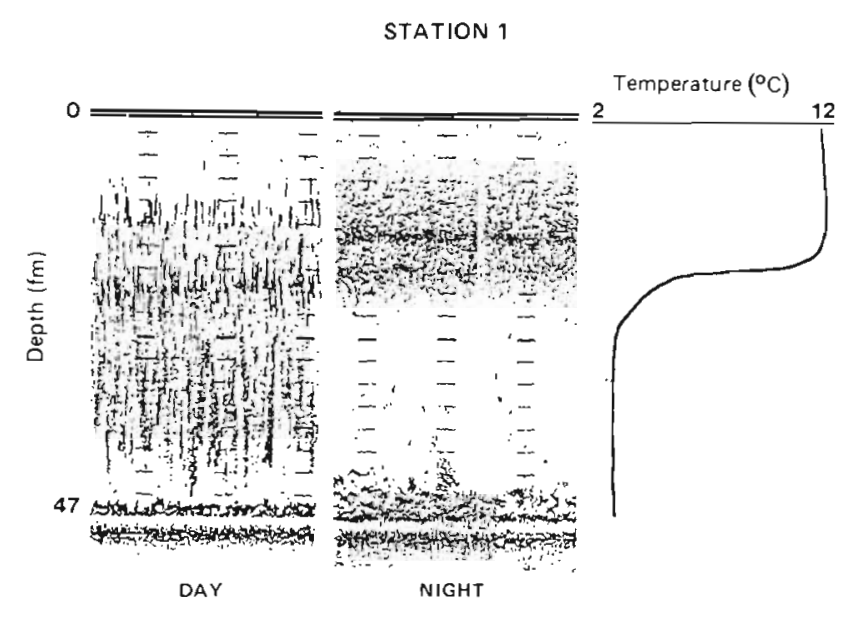

Fig. 3. Stn 1: day and night acoustic signals compared with temperature profile. Depth in fathoms $(1 \mathrm{fm}=1.83 \mathrm{~m})$

Juveniles occurring in stomachs of adult pollock caught during Eastern bottom trawls at Stn 1 were comprised entirely of fish 60 to $90 \mathrm{~mm}$. The smaller size mode of pollock which was present in surface layer trawls was absent from stomach contents. The adult stomach contents from Stn 1 appeared to reflect the daytime distribution of juveniles in the bottom layer; somewhat smaller fish in stomachs compared with daytime bottom trawl catches (major length modes of 70 to 79 and 80 to $89 \mathrm{~mm}$, respectively) could indicate either selection for smaller fish by the predators or relatively poor retention of smaller fish by the trawls.

Acoustic observations at Stn 2 also indicated the prevalence of juvenile fish in the surface layer at night and a major component migrating down in daytime (Fig. 5). Fish were smaller here than at Stn 1, with the length mode centered between 30 and $50 \mathrm{~mm}$ (Fig. 6). These small juveniles were abundant in daytime midwater trawls in the bottom layer, in contrast with the observation that only larger fish occurred in the bottom layer in daytime at Stn 1 (note that Stn 2 was shallower, but still thermally stratified). At night, juveniles were nearly 10 times more abundant in the surface layer than in the bottom layer. This pattern reversed in the daytime, indicating downward migration in daytime and upward migration at night. In daytime midwater trawls, fish 40 to $60 \mathrm{~mm}$ were relatively abundant in the bottom layer compared with the surface, indicating some size stratification, or alternatively, daytime avoidance of the trawls by larger fish in the surface layer.

Juveniles found in stomachs of adult pollock caught in bottom trawls at Stn 2 were mostly 40 to $60 \mathrm{~mm}$ fish, reflecting the size range of fish caught in Marinovich trawls.

Other midwater trawl stations were not occupied for $24 \mathrm{~h}$, but usually showed the daytime or nighttime patterns described above. For example, in daytime at
Station 1

Nighttime trawl catches

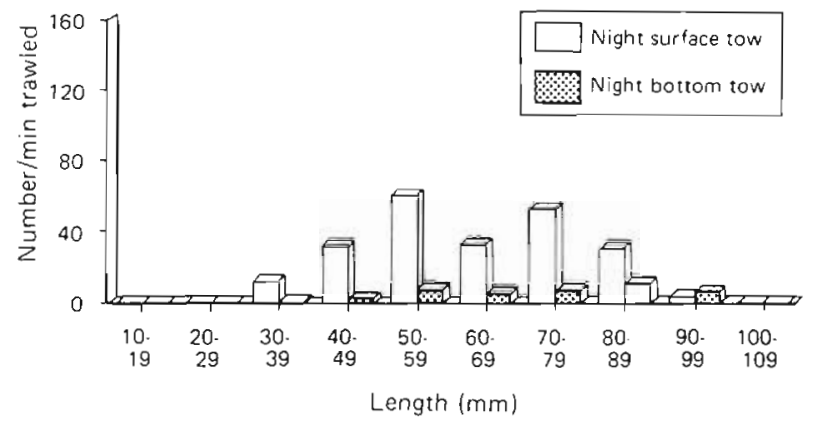

Daytime trawl catches

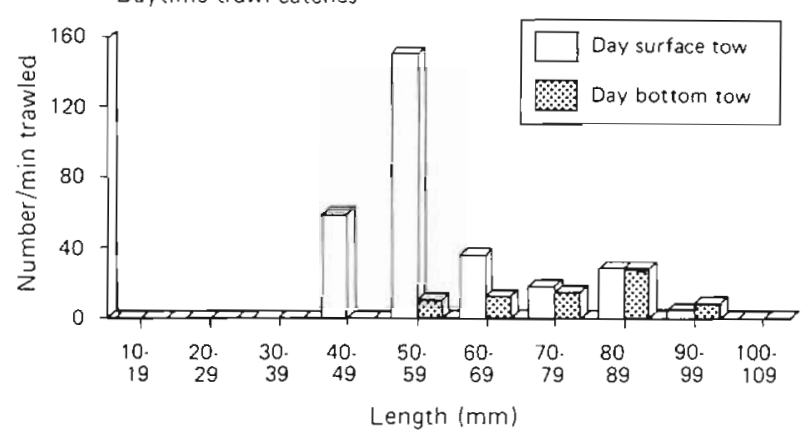

Pollock in adult stomachs

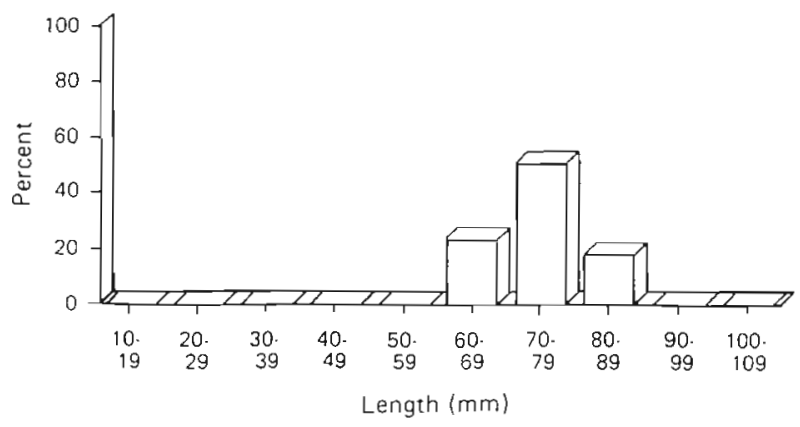

Fig. 4. Theragra chalcogramma. Stn 1. length frequencies of juvenile walleye pollock in night (top) and day (middle) midwater trawl catches from surface and bottom layers, and in adult stomach contents (bottom)

\section{STATION 2}

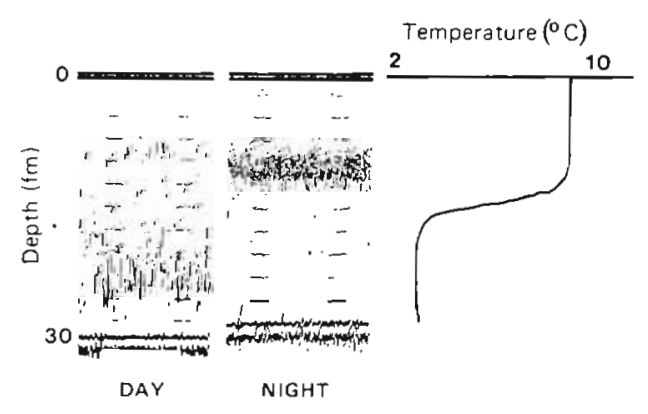

Fig. 5. Stn 2: day and night acoustic signals compared with temperature profile 

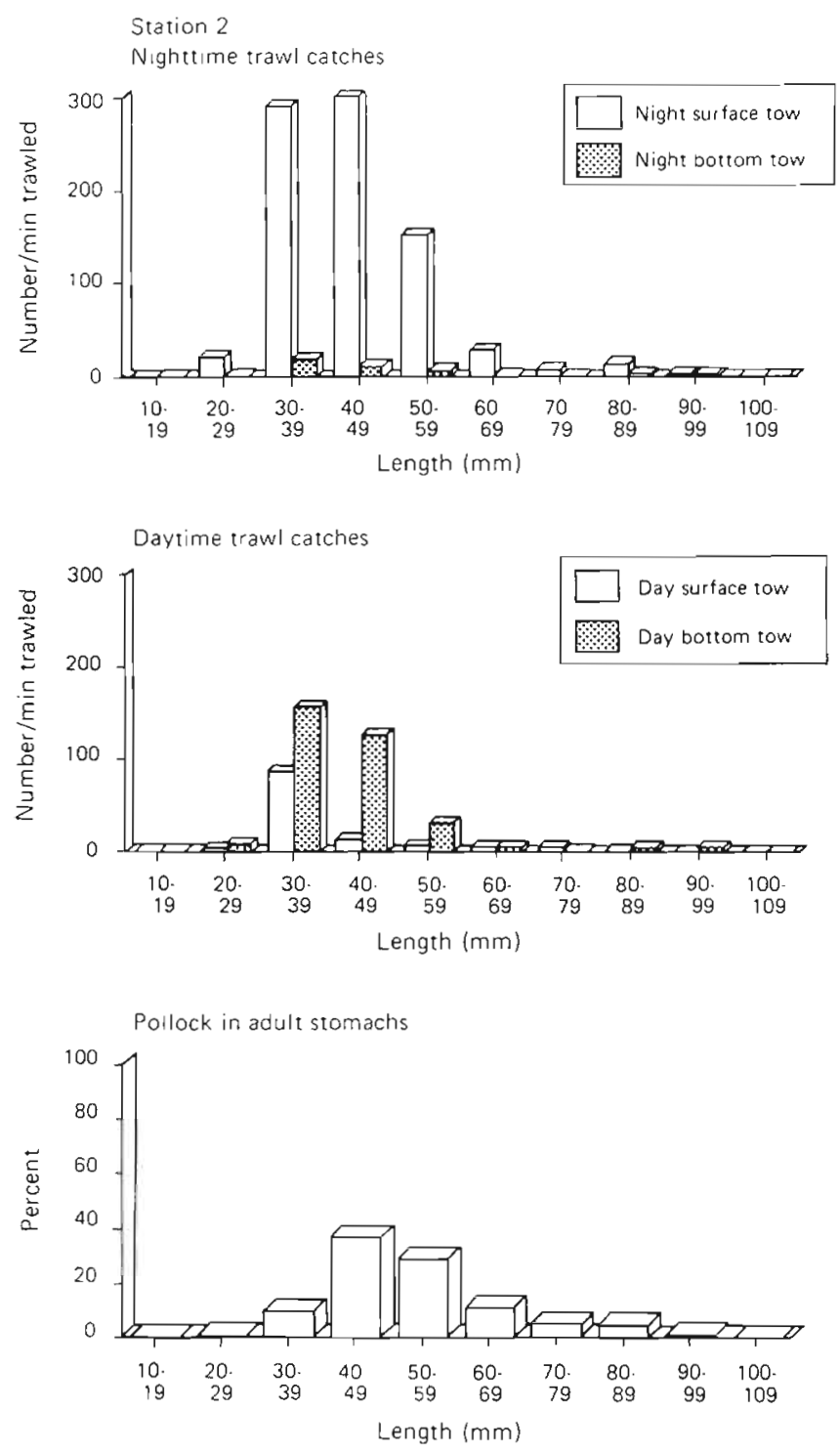

Fig. 6. Theragra chalcogramma. Stn 2: length frequencies of juvenile walleye pollock in night (top) and day (middle) midwater trawl catches in surface and bottom layers, and in adult stomach contents (bottom)

Stn 3, acoustic observations and surface and bottom layer midwater trawls indicated that fish were distributed throughout the water column, and larger fish were located on the bottom (Figs. 7 and 8). The stomach contents of adult pollock from Eastern bottom trawls was comprised of fish 60 to $90 \mathrm{~mm}$, reflecting the size range of juveniles in the bottom layer.

Stn 4 appeared to be anomalous compared with the above distribution patterns. At other stations the scattering layer became more diffuse around 07:30 h (sunrise was 05:00 h) and vertically oriented scattering aggregates were observed (Figs. 3, 5 and 7). At dusk, about 21:30 h (sunset 19:00 h), the scattering layer
STATION 3

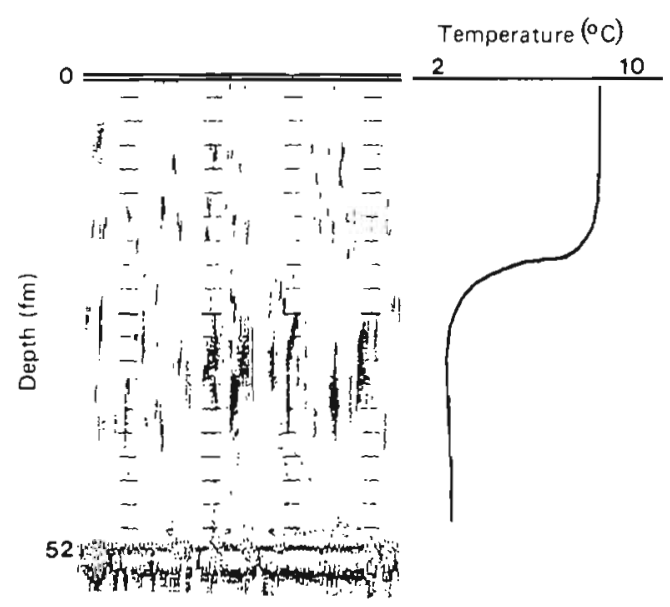

Fig. 7. Stn 3: daytime acoustic signals compared with temperature profile

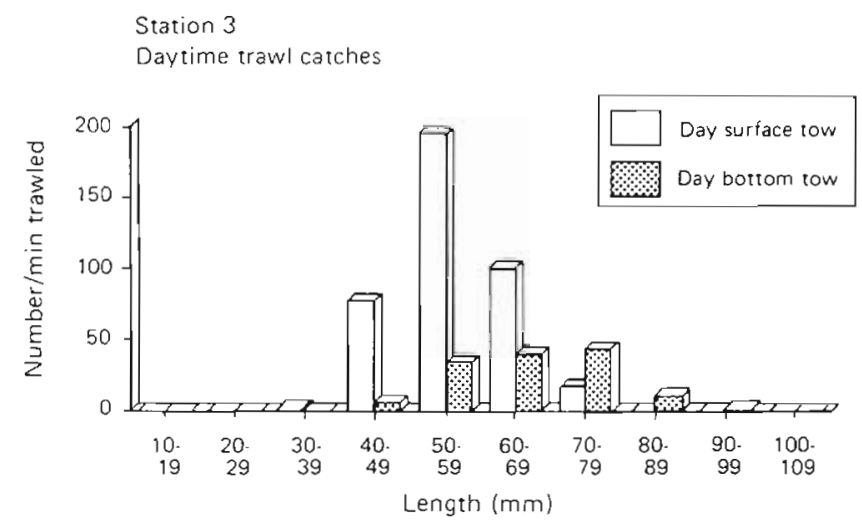

Pollock in adult stomachs

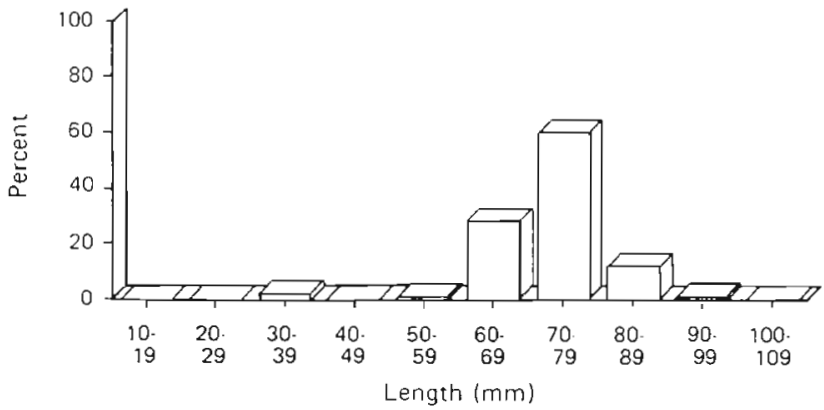

Fig. 8. Theragra chalcogramma. Stn 3: length frequencies of juvenile walleye pollock in daytime midwater trawl catches in surface and bottom layers (top) and in adult stomach contents (bottom)

concentrated near the thermocline. At Stn 4, 2 size modes of juveniles were located in the surface layer in early morning (Fig. 9). From acoustic observations taken continuously from 06:00 until 09:30 h, when 


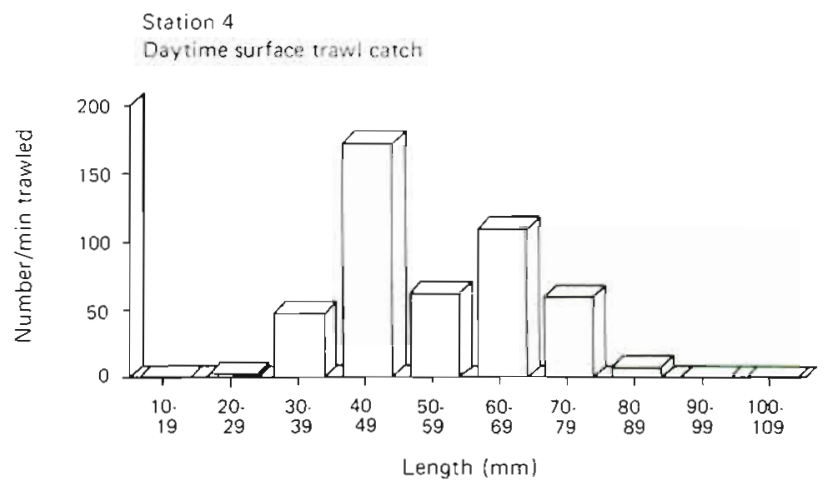

Fig. 9. Theragra chalcogramma. Stn 4: length frequency of juvenile walleye pollock in daytime midwater trawl catch in surface layer. Adults were not cannibalistic at this station

occupation of the station was terminated, juveniles did not appear to have migrated below the thermocline, and remained in the surface layer (Fig, 10). Nearbottom sign was mostly adult pollock. There was no

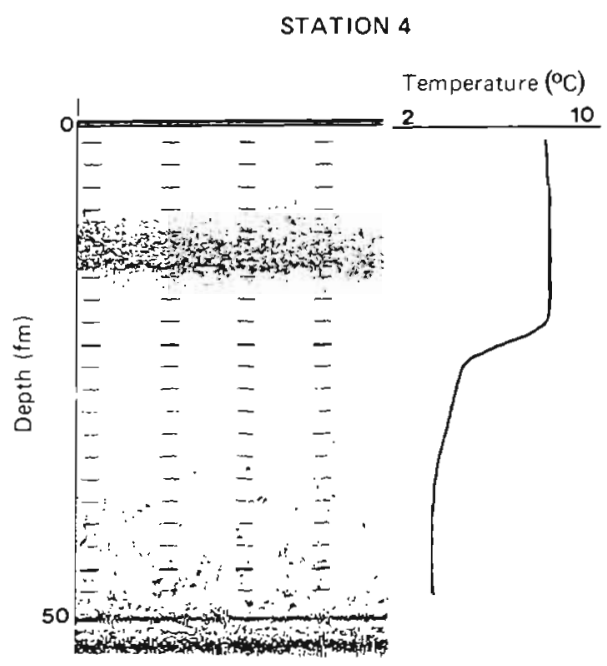

Fig. 10. Stn 4: daytime acoustic signals compared with temperature profile

evidence of cannibalism in the stomachs of 64 adults examined, further supporting the suggestion that age-0 juveniles at this location were not migrating vertically.

\section{Cannibalism}

Evidence of juvenile walleye pollock in the stomachs of adult pollock was found at $81 \%$ (69/85) of bottom trawl stations (Table 1). Adults ranged from 30 to $75 \mathrm{~cm}$ in length. Twenty-nine percent (437/1503) of the stomachs contained juvenile pollock, with an average of 3.0 juveniles per adult pollock stomach. All juvenile pollock found in stomachs of adults were age-0 fish, ranging in length from 20 to $100 \mathrm{~mm}$. The overall mean prey length was $61 \mathrm{~mm}$, but the distribution was bimodal with peaks at 50 and $70 \mathrm{~mm}$. There was a slight but significant negative correlation between mean prey and predator lengths (prey length $(\mathrm{mm})=$ $84.8-0.32 \times$ predator length $(\mathrm{mm}) ; \quad r=-0.17$, $0.005<p<0.01$ ). This relationship appeared to result from geographical distributions where smaller predators overlapped with larger prey.

Cannibalism varied by time of day. Percent of hauls with cannibalism, percent of adults that were cannibalistic and number of juvenile prey per adult pollock stomach were all lowest at night (21:00 to 06:00 h) and highest late in the day $(14: 00$ to $21: 00 \mathrm{~h})$ (Table 1). Some evidence of cannibalism was expected in all hours since the period of digestion is longer than $24 \mathrm{~h}$ (Dwyer et al. 1987).

\section{Prey abundance and recent growth history}

Zooplankton abundance, and juvenile feeding and growth were compared at 3 stations (1,2 and 4) where night-time bongo tow (to minimize net avoidance) and Marinovich midwater trawl data were available.

Ninety-three fish between 50 and $60 \mathrm{~mm}$ length were examined for stomach contents. Stomachs contained: copepods greater than $3 \mathrm{~mm}$ prosome length $(60 \%$ by weight); copepods smaller than $3 \mathrm{~mm}(4 \%)$; euphausiids $(7 \%)$; crab larvae $(7 \%)$; and miscellaneous organisms and unidentifiable matter $(22 \%)$.

Growth rates of individual fish for the $10 \mathrm{~d}$ before capture were determined from otolith preparations, by measuring the distance covered by the last 10 incre-

Table 1 Theragra chalcogramma. Cannibalism of juveniles by adult pollock by time of day in August-September 1984 . Sunrise $05: 00 \mathrm{~h}_{\text {; }}$ dusk 21:00 h

\begin{tabular}{|c|c|c|c|c|}
\hline & $\begin{array}{c}\text { Night } \\
\text { 21:00-06:00 h }\end{array}$ & $\begin{array}{c}\text { Early day } \\
06: 00-4: 00 \mathrm{~h}\end{array}$ & $\begin{array}{c}\text { Late day } \\
14: 00-21: 00 \mathrm{~h}\end{array}$ & Total \\
\hline No. of hauls & 24 & 33 & 28 & 85 \\
\hline No of stomachs & 402 & 624 & 477 & 1503 \\
\hline$\%$ Hauls with cannibalism & 62.5 & 81.8 & 96.4 & 81.2 \\
\hline$\%$ Adults cannibalistic & 13.7 & 24.4 & 48.2 & 29.1 \\
\hline No. juvenile prey per adult & 1.4 & 2.4 & 5.3 & 3.0 \\
\hline
\end{tabular}


ments on the anterior edge and assuming a linear relationship between otolith radius (from the focus to the anterior edge) and fish length. This relationship was: fish length $(\mathrm{mm})=12.7+43.7 \times$ otolith radius $(\mathrm{mm})(r=0.96, n=48)$. Growth rates were significantly different at the 3 stations (Kruskal-Wallis $H$ statistic $=$ 17.57, $p<0.001$ ). Growth rates were highest at Stn 4 , suggesting a relationship to the high zooplankton abundance there (Table 2).

\section{DISCUSSION}

Vertical migration patterns of age-0 gadids vary with species, size, season and location. Koeller et al. (1986) noted that in the Northwest Atlantic larger age-0 Atlantic cod Gadus morhua (40 to $100 \mathrm{~mm}$ ) in June migrated up at night and down in daytime. In the North Sea, age-0 cod (60 to $130 \mathrm{~mm}$ ) in August are found mostly on bottom, with smaller individuals (60 to $70 \mathrm{~mm}$ ) found in midwater during the night (Bailey 1975). Haddock Melanogrammus aeglefinus (60 to $150 \mathrm{~mm}$ ) in the North Sea were reported to migrate from midwater at dusk to the bottom at dawn in August, although some portion remained in midwater during the day (Bailey 1975). Haddock in the Northwest Atlantic were reported to occur near the surface during day and night in June, and they were observed to make on ontogenetic shift in depth from a pelagic to benthic habitat when they attained a length of about 70 to $80 \mathrm{~mm}$ from mid-June to August (Koeller et al. 1986, Mahon \& Neilson 1987). Silver hake Merluccius bilinearis (greater than $20 \mathrm{~mm}$ ) in October in the Northwest Atlantic and Norway pout Trisopterus esmarki (45 to $100 \mathrm{~mm}$ ) in the North Sea in June were reported to migrate vertically up at night and down in the day; and whiting Merlangius merlangus (85 to $160 \mathrm{~mm}$ ) did not show clear evidence of vertical migration (Bailey 1975 , Koeller et al. 1986).

In the present study, although patterns of vertical migration of juvenile walleye pollock varied among different locations, generally the largest fish migrated from their nighttime distribution in the surface layer to the bottom layer in daytime. Relatively few tows were made at the diel stations, and gear avoidance, especially in daytime, is recognized as a sampling problem when using trawl data to study fish behavior (Bailey 1975). However, high catch rates of large juvenile pollock were attained in daytime surface layer tows, e.g. Stn 4. Furthermore, the results from the trawl data are supported by acoustic observations and by analysis of adult stomach contents.

Cannibalism was prevalent in the present study and vertical distribution of juveniles appeared to be an important factor in its occurrence. Adult pollock are located deep in the water column, generally near bottom over the continental shelf and slope (Maeda 1986, Traynor 1986). In daytime, adult walleye pollock are closer to the bottom (Okada 1986). In the present study, the length ranges of juvenile walleye pollock in the stomachs of adults reflected the length ranges of juveniles in the bottom layer in daytime. Furthermore, heavy cannibalism occurred when a strong scattering layer existed in the bottom layer, usually in daytime. Because the incidence of heavy cannibalism was highest in daytime, it appears that adults consumed juveniles in daytime when both were near bottom. Cannibalism by adult walleye pollock in daytime was also indicated by the results of Mito (1974).

Francis \& Bailey (1983) proposed an interaction between cannibalism and water column stratification. In summer, age-0 pollock are located in the upper mixed layer and adults rarely consume them (Maeda 1986, Dwyer et al. 1987). Francis \& Bailey (1983) proposed that cannibalism occurred after water column mixing (induced by autumn storms and surface cooling) caused destratification and subsequent recruitment of juveniles to the bottom layer habitat of adults. While this may happen in some areas, this study refutes the general applicability of this hypothesis. Juveniles were frequently caught below a strong thermocline and heavy cannibalism occurred at 17 of 36 stations where the water column was highly stratified.

What causes the juveniles to vertically migrate and thus become vulnerable to heavy cannibalism remains speculative. The benefits of migration must outweigh the increased risk of cannibalism. The variability in length of migrating or nonmigrating individuals in our

Table 2. Theragra chalcogramma. Mean growth rates of juvenile (50 to $60 \mathrm{~mm}$ length) walleye pollock over the last $10 \mathrm{~d}$ prior to capture as determined from otolith growth and otolith increment counts at Stn 1, 2 and 4. Zooplankton biomass (wet wt) at those stations is also reported

\begin{tabular}{|c|c|c|c|c|c|}
\hline Station & $\begin{array}{l}\text { Mean length of last } 10 \\
\text { increments mm (SE) }\end{array}$ & $n$ & $\begin{array}{l}\text { Mean growth rate } \\
\qquad\left(\mathrm{mm} \mathrm{d}^{-1}\right)\end{array}$ & $\begin{array}{l}\text { Zooplankton wet wt } \\
\left(\mathrm{g} 10 \mathrm{~m}^{-2}\right)\end{array}$ & $\begin{array}{l}\text { Large copepod wet wt } \\
\left(\mathrm{g}^{\mathrm{g}} 10 \mathrm{~m}^{-2}\right)\end{array}$ \\
\hline 1 & $0.168(0.027)$ & 26 & 0.734 & 151.9 & 22.9 \\
\hline 2 & $0.155(0.036)$ & 21 & 0.677 & 87.6 & 25.1 \\
\hline 4 & $0.192(0.036)$ & 17 & 0.839 & 1256.4 & 539.6 \\
\hline
\end{tabular}


study indicates that migration of walleye pollock is not a simple function of size, as indicated for some other fishes (Boehlert 1982, Mahon \& Neilson 1987). Vertical migration of some fishes may be initiated by the upward movement or aggregation of prey at night (Brawn 1960, McNaughton \& Hasler 1961). This remains a possibility in the case of walleye pollock, especially for larger $(70$ to $80 \mathrm{~mm}$ ) juveniles whose primary food is comprised of euphausiids. Euphausids typically exhibit strong diurnal vertical migration (e.g. Marlowe \& Miller 1975, Frost \& McCrone 1979). Other possible causes of vertical migration are the avoidance of daytime surface feeding predators, such as birds (Hunt et al. 1981), or a relationship with the movement of medusae, which are associated with juvenile walleye pollock (W. Hamner, Biology Dept, Univ, of Calif., Los Angeles, pers. comm.) and other juvenile gadids (Bailey 1975, Koeller et al. 1986).

It is suggested here that the vertical migration of age- 0 juveniles is related to food availability. At most stations juvenile walleye pollock, especially the larger individuals, were migrating vertically. However, at Stn 4 where zooplankton biomass was high, age-0 walleye pollock, including large individuals, either were not migrating vertically or their downward movement from the warm surface layer was delayed several hours. Their recent growth was higher compared with the 2 stations where fish were migrating vertically and where zooplankton abundance was low. At Stn 2, where the zooplankton biomass and pollock growth rates were lowest, even small juveniles vertically migrated into the bottom layer. Thus when food is abundant it may be an advantage for age-0 walleye pollock to remain in the warm upper layers, and when food is less abundant, they may migrate vertically.

Several experimental studies have indicated an interaction between food deprivation and temperature preference in fishes (Ehrlich et al. 1979, Olla et al. 1985). In general, vertical migration is efficient energetically if the cost of migration is less than the energy saved from being in waters of lower temperature where their metabolic demands are less (Brett \& Groves 1974). The experimental results of Smith et al. (1986) indicate an energetic advantage of diurnal vertical migration to juvenile walleye pollock when they are deprived of food; at low levels of food availability, growth was favored by low temperatures; however, when food was abundant, maximum food intake and growth were proportional to temperature. Given the above theoretical arguments and the observations made in this study, the role of energetics in the onset of vertical distribution of juvenile fishes merits more consideration in future experimental and field studies.
Acknowledgements. I thank J. Traynor, S. Hinckley, M. Yoklavich, A. Kendall and 3 anonymous reviewers for their comments on the manuscript, and C. L. Stehr and A. Brown for laboratory assistance.

\section{LITERATURE CITED}

Bailey, K. M., Dunn, J. (1979). Spring and summer foods of walleye pollock. Theragra chalcogramma, in the eastern Bering Sea. Fish. Bull. U.S. 77: 304-308

Bailey, K. M., Stehr, C. L. (1988). The effects of feeding periodicity and ration on the rate of increment formation in otoliths of larval walleye pollock Theragra chalcogramma (Pallas). J. exp. mar. Biol. Ecol. 122: 147-161

Bailey, R. S. (1975). Observations on diel behaviour patterns of North Sea gadoids in the pelagic phase. J. mar. biol. Ass. U.K. 55: 133-142

Boehlert, G. W. (1982). Ontogenetic changes in growth and their relationship with temperature and habitat change. In: Calliet, G. M., Simenstad, C. A. (eds.) Gutshop '81: Fish food habits studies, proceedings of the third Pacific workshop. Washington Sea Grant, Univ. of Washington, Seattle p. $115-123$

Brawn, V.W. (1960). Seasonal and diurnal vertical distribution of herring (Clupea harengus L.) in Passamaquoddy Bay, N.B. J. Fish. Res. Bd Can. 17: 699-771

Brett, J. R., Groves, T. D. (1974). Physiological energetics. In: Hoar, W. S., Randall, J. R., Brett, J. R. (eds.) Fish Physiology. Academic Press, New York, p. 280-352

Dwyer, D. A., Balley, K. M., Livingston, P. A. (1987). Feeding habits and daily ration of walleye pollock (Theragra chalcogramma) in the eastern Bering Sea, with special reference to cannibalism. Can. J. Fish. Aquat. Sci. 11. 1972-1984.

Ehrlich, K. F., Hood, J. M., Muszynski, G., McGowen, G. E. (1979). Thermal behavioral responses of selected California littoral fishes. Fish. Bull. U.S. 76: 837-849

Francis, R. C., Bailey, K. M. (1983). Factors affecting recruitment of selected gadoids in the northeast Pacific and east Bering Sea. In: Wooster, W. S. (ed.) From year to year. Washington Sea Grant, Univ, of Washington, Seattle, p. $35-60$

Frost, B. W., McCrone, L. E. (1979). Vertical distribution, diel variation and abundance of some mesopelagic fishes in the eastern subarctic Pacific Ocean in summer. Fish. Bull. U.S 76: $751-770$

Hunt, G. L., Burgeson, B., Sanger, G. A. (1981). Feeding ecology of seabirds of the eastern Bering Sea. In: Hood, D. W., Calder, J. A. (eds.) The eastern Bering Sea shelf: oceanography and resources, Vol. 2. Office of Marine Pollution and Assessment, Juneau, Alaska, p. 629-648

Koeller, P. A., Hurley, P., Perley, P., Neilson, J. D. (1986). Juvenile fish surveys on the Scotian Shelf: implications for year-class size assessments. J. Cons. int. Explor. Mer 43: $59-76$

Maeda, T. (1986). Life cycle and behavior of adult pollock (Theragra chalcogramma Pallas) in waters adjacent to Funka Bay, Hokkaido Island. Int. North Pac. Fish. Comm. Bull. 45: 39-65

Mahon, R., Neilson, J. D. (1987). Diet changes in Scotian Shelf haddock during the pelagic and demersal phases of the first year of life. Mar Ecol. Prog. Ser. 37: 123-130

Marlowe, C. J., Miller, C. R. (1975). Patterns of vertical distribution and migration of zooplankton at Ocean Station 'P'. Limnol. Oceanogr. 20: 824-844 
McNaughton, N. C., Hasler, A. D. (1961). Surface schooling and feeding behavior of the white bass, Roccus chrysops (Rafinesque), in Lake Mendota. Limnol. Oceanogr. 6: $53-60$

Mito, K. (1974). Food relationships among benthic fish populations in the Bering Sea. M.S. thesis, Univ. of Hokkaido, Japan, p. 135

Nishimura, A., Yamada, J. (1984). Age and growth of larval and juvenile walleye pollock Theragra chalcogramma (Pallas) as determined by otolith daily growth increments. J. exp. mar. Biol. Ecol. 82: 191-205

Nishiyama, T., Hirano, K., Haryu, T (1986). The early life history and feeding habits of larval walleye pollock, Theragra chalcogramma (Pallas), in the southeast Bering Sea. Int. North Pac. Fish. Comm. Bull. 45: 177-227

Okada, K. (1986). Biological characteristics and abundance of

This article was submitted to the editor pelagic pollock in the Aleutian Basin. Int. North Pac. Fish. Comm. Bull. 45: 150-176

Olla, B. L., Studholme, A. L., Bejda, A. J. (1985). Behavior of juvenile bluefish Pomatomus saltatrix in vertical thermal gradients: influence of season, temperature acclimation and food. Mar. Ecol. Prog. Ser. 23: 165-175

Smith, R. L., Paul, A. J., Paul, J. M. (1986). Effect of food intake and temperature on growth and conversion efficiency in juvenile walleye pollock (Theragra chalcogramma) (Pallas), a laboratory study. J. Cons. int. Explor. Mer 42: $241-253$

Traynor, J. J. (1986). Midwater abundance of walleye pollock in the eastern Bering Sea, 1979 and 1982. Int. North Pac. Fish. Comm. Bull. 45: 121-135

Zar, J. H. (1984). Biostatistical analysis, 2nd edn. PrenticeHall, Englewood Cliffs, New Jersey

Manuscript first received: September 29, 1988

Revised version accepted: February 17, 1989 